\title{
A note on the Bitcoin and Fed Funds rate
}

\author{
Sofiane Aboura ${ }^{1}$
}

Received: 28 June 2021 / Accepted: 8 January 2022 / Published online: 18 February 2022

(c) The Author(s), under exclusive licence to Springer-Verlag GmbH Germany, part of Springer Nature 2022

\begin{abstract}
This study examines the potential influence of the Federal Reserve policy on Bitcoin price dynamics. The empirical investigation is based on methodologies to quantify the influence of the Fed Funds rate on Bitcoin through linear, nonlinear, and spillover effects. It covers a set of six representative assets, including Bitcoin, Fed Funds rate, S\&P 500, 10-year US Treasury Bond, USD/EUR, and Gold from January 2015 to February 2021. Evidence is provided that Fed Funds rates have nonlinear effects and temporarily strong spillover effects on Bitcoins.
\end{abstract}

Keywords Bitcoins $\cdot$ Fed Funds rates $\cdot$ Spillovers $\cdot$ Financial markets

JEL Classification C58 · G15 $\cdot$ E44

\section{Introduction}

This paper investigates the role played by Fed Funds rates on Bitcoin price dynamics. The 2020-2021 bull run of Bitcoin prices reaches an all-time high above $\$ 60,000$. The trend toward industry adoption of cryptocurrencies by adding Bitcoins to their balance sheet has fueled intense public interest in Bitcoin as a credible private means of payment. While it had a virtually value of zero in US Dollar at the time it was established by the presumed Satoshi (Nakamoto 2008), it has become a channel of capital inflow catapulting its market value up to $\$ 1$ trillion. Bitcoin has become the world's first decentralized cryptocurrency, with the largest share $(17.60 \%)$ in the total capitalization of cryptocurrency markets. ${ }^{1}$

$\triangle$ Sofiane Aboura

Sofiane.Aboura@univ-paris13.fr

1 Université de Paris XIII, Sorbonne Paris Cité, 93430 Villetaneuse, France

1 coinmarketcap.com. 
Interestingly, the Bitcoin concept emerged in the wake of the financial crisis on October $31,2008 .^{2}$ Hence, it is likely that Bitcoin ${ }^{3}$ birth may have been a direct response to the global financial crisis (see, e.g., Fantacci and Gobbi 2021). In the same vein, more recently, a dramatic run-up in cryptocurrencies can be observed in the wake of another planetary crisis, when the World Health Organization declared COVID-19 on March 11,2020 , a world pandemic. There is a rich collection of papers discussing the very nature ${ }^{4}$ of private digital currencies, particularly on whether they are real currencies or commodity-like assets (see, e.g., Gronwald 2019; Balvers and McDonald 2021; Obstfeld 2021).

In both situations, the FED lowered its rates by $100 \mathrm{bp}$ to face the financial crisis and the coronavirus outbreak in December 16, 2008, and March 16, 2020; other open market interventions occurred mostly by $-25 \mathrm{bp}$, once by $-50 \mathrm{bp}$ on March 3 , 2020. On March 16, 2020, the Fed Fund rates reached their largest one-day decline ( $-77.27 \%$ ) since 1961 from 1.1 to $0.25 \%$. As exhibited in Fig. 1, the decline is pursued below $0.1 \%$ on August 18, 2020, where at the same time, Bitcoin accelerated its rally, pushing the prices from 5,074 (March 16, 2020) to 10,007 (May 7, 2020), 21,384 (December 16, 2020), 32,127 (January 4, 2021), 40,666 (January 8, 2021), 52,269 (February 17, 2021) and 61,130 (March 13, 2021): The Bitcoin price was multiplied by 12 from March 16, 2020, to March 13, 2021. In addition, the magnitude of these two substantial interest rate cuts might not have been expected, although there occurrence is a logical consequence of the Federal Reserve dual mandate given the Federal Reserve Act. Indeed, Fed policy adjustments, stated in terms of monetary policy reactions to macroeconomic fluctuations, aimed at stabilizing the general level of prices (inflation-targeting). Although sometimes, Fed interventions have been suspected to act to prevent widespread losses in financial markets. The "Fed put" terminology signifies that Fed interventions aimed at implicitly preventing stock price declines beyond a proper level (Poole 2008). The Fed put argument has been observed and discussed since the 1990s by several empirical articles, some of which tend to indicate the existence of such policy of targeting stock prices (see, e.g., D'Amico and Farka 2011; Cieslak and Vissing-Jorgensen 2020), while others simply confirm the reaction of the stock market to the federal funds rate (e.g., Bernanke and Gertler 1999; Rigobon and Sack 2004). The mechanism by which Fed policy might impact Bitcoins is when a one-time cut rate is surprisingly large, pushing the real interest rate in their negative territory, which may have redirected capital inflows to private digital coins. ${ }^{5}$

\footnotetext{
2 https://satoshi.nakamotoinstitute.org/emails/cryptography/1/.

3 Note that the concept of private means of payment did emerge far before Bitcoin (see, for instance, Chaum (1983) for a discussion on automated payments with blind signatures based on cryptography). Satoshi (Nakamoto 2008) renews the practical interest in digital currencies by solving the double-spending problem using a peer-to-peer network.

4 The argument most cited against the market of digital coins is there absence of intrinsic value since they are not backed by any kind of assets and not supported by any sort of state regulation. An opposite view can be found in Hayek (1990) on "why a government monopoly of the provision of money is universally regarded as indispensable").

5 See, for instance, Elon Musk view on Bitcoins: "When fiat currency has negative real interest, only a fool wouldn't look elsewhere.”-Elon Musk (@elonmusk) February 19, 2021. Earlier, Tesla announced in an SEC filing that it bought \$1.5 billion worth of Bitcoins in February 8, 2021.
} 


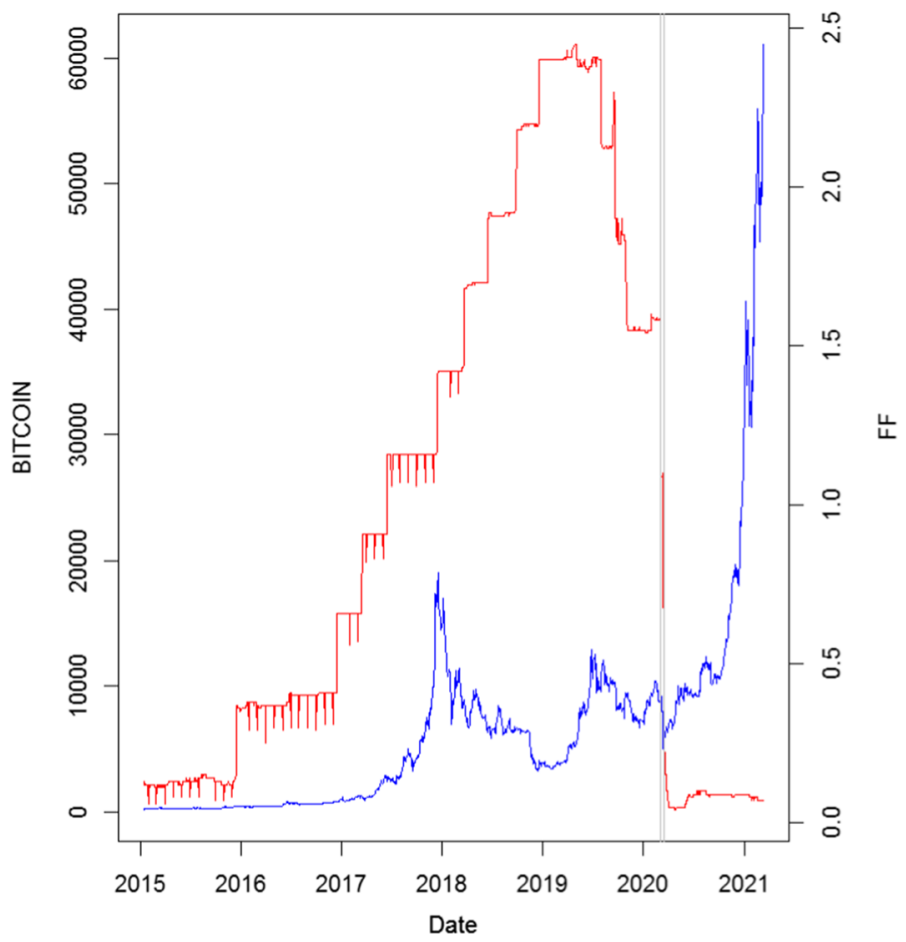

Fig. 1 Bitcoin price versus Fed Fund rates. Note: Figure 1 displays the evolution of Bitcoin prices and Fed Fund rates. The two gray vertical lines correspond exactly to March 3 and 16, 2020, when the Fed Fund rates were cut, respectively, by 50 bp and 100 bp. Period: 01/01/2015-02/28/2021

This paper employs alternative methodologies to investigate the relation between Fed Funds rates and Bitcoins. In the first step, it examines the contemporaneous and lagged linear relation. However, Fed Funds rates do not vary on a daily basis, which limits their influence as captured by standard OLS, making their estimate rarely statistically significant. This might explain why most of the studies on Bitcoins have picked up long-term rates instead of short-term rates and more generally have ignored Fed Funds rates in their econometric setting. For that reason, in a second step, the examination is complemented under a nonlinear framework by analyzing the threshold and higherorder effects. However, this setting may capture permanent nonlinear features among Fed rates and Bitcoins but not necessary temporary features that occur at one given time. For that reason, in a third step, this paper adopts the methodological approach of Diebold and Yilmaz $(2009,2014)$ to investigate the spillover effects from Fed Funds rates to Bitcoin prices. They use variance decompositions in vector autoregressions to assess dependencies among variables. They quantify the intensity of interdependence across assets and allow a decomposition of spillover effects between source and recipient variables. This method offers several advantages, including a two-way relationship between variables and the tracking of the evolution of spillovers over time. This approach has been employed by several recent articles (Greenwood-Nimmo et al. 2016; Do et al. 2016; Barunik et al. 2016; Finta and Aboura 2020, etc.). The choice of 
such a setup is motivated by the interest in computing directional spillovers to identify the transmitters of shocks to Bitcoin price returns on a temporary basis.

The contribution of this paper is to quantify (threshold, higher order, and spillover effects) the influence of Fed Funds rates on Bitcoin price returns. The dataset includes time series of daily observations from 01/01/2015 to 02/28/2021 on representative financial assets (S\&P 500 Stock Index, 10-year US Government Bond, Fed Funds rates, USD/EUR Exchange rates, Gold). The dataset is extended to account for macrofinancial spillover effects through additional US economic variables (Nominal FRB, Weekly Initial Claim, Industrial Production Index, Total Nonfarm Payroll, Consumer Price index). Among the cryptocurrencies, only Bitcoin is investigated because it is the most representative among its peers, as it has launched the deployment of a variety of new cryptocurrencies since 2009.

The main finding emphasizes the influence of Fed Funds rates on Bitcoin prices. The article is organized as follows. Section 2 displays the literature review. Section 3 outlines the methodology employed. Section 4 presents the data description. Section 5 discusses the empirical findings. Finally, Sect. 6 concludes.

\section{Related literature}

Cryptocurrencies are becoming among the largest Over-the-Counter markets in the world. The literature on cryptocurrencies has been following a dramatic rise since their inception because there are still several pending questions on how such private money has skyrocketed so rapidly. In addition, despite hundreds of papers on that subject, it seems unclear to identify the key drivers of Bitcoin and its peers. Beyond the fact that this is not a mature market, there is still some heterogeneity in the explanatory power of crypto-market factors and, in particular, regarding Bitcoin price returns. To that end, Koutmos (2020) discusses why studies have difficulty linking Bitcoin prices to economic fundamentals overall when not considering exchange rate regimes. However, another possible explanation is price manipulation in the Bitcoin ecosystem, where suspicious trades might justify the abnormal returns, as suggested by Gandal et al. (2018). Griffin and Shams (2020) also defend the view that price manipulation can have substantial distortive effects in cryptocurrencies, which means that their price reflects much more than standard supply/demand and fundamental news. Foley et al. (2019) go further by claiming that one-quarter of Bitcoin users are involved in illegal activity. However, the popular success of Bitcoins cannot be simply reduced to these factors, since several articles find clear economic determinants of these crypto-assets. Papers related to our research question can be broadly classified into two categories: studies that discuss Bitcoin determinants and studies that discuss the links between cryptocurrencies and other markets. Hereafter, we exposed some of the recent studies that investigate which variable is most likely explaining cryptocurrency prices and volatility behavior.

The first stream of studies examines Bitcoin determinants. Conrad et al. (2018) use the GARCH-MIDAS model to investigate the economic determinants of long-term Bitcoin volatility with different assets (2013-2017); they find that Bitcoin volatility increases with higher levels of global economic activity. Lyocsa et al. (2020) use stan- 
dard asset pricing factor models to study whether major cryptocurrencies comove with stocks, currencies, commodities, macroeconomic factors, and cryptocurrency marketspecific factors (2011-2018). They conclude that cryptocurrency returns have low exposures to standard asset classes (stocks, currencies, and commodities); however, they note that returns of cryptocurrencies can be predicted by two factors specific to these markets (momentum and investors' attention). Mamun et al. (2020) use the DCC-GJR-GARCH specification to examine the role of geopolitical risk in Bitcoin investment (2010-2015); they highlight that geopolitical risk and US economic policy uncertainty are far more significant during unfavorable economic conditions. Three studies add the Fed Funds rates to the economic determinants of bitcoins. Panagiotidis et al. (2018) employ Lasso regression for variable selection among 21 variables likely to affect Bitcoin Price Index returns (2010-2017); they find that search intensity on Google, gold, and policy uncertainty is mostly important and are followed by stock markets, exchange rates, oil, and interest rates. Panagiotidis et al. (2019) employ VAR/FAVAR models to gauge the interaction between 19 variables and Bitcoin returns (2010-2018). They notice that Bitcoin may react positively to a federal funds rate rise but reacts negatively to a rise in the ECB deposit facility rate. Interestingly, they add "such an argument is hard to corroborate... Therefore, further research on bitcoin's response to central bank rates shocks is required." Dyhrberg (2016) uses a GARCH framework where lagged variables (Fed Funds rate, gold, exchange rate, stock index) are nested in the mean equation to observe if they affect the Bitcoin prices (20102015); lagged Fed Funds rates significantly affected the bitcoin price, which points to bitcoin acting like a currency. A series of articles employ artificial intelligence models to predict more than explain Bitcoin (nonlinear) price movements. Jang and Lee (2018) use Bayesian neural networks fed with economic and technological variables (20112017). They find that this approach can successfully explain Bitcoin price time series. Adcock and Gradojevic (2019) use several nonparametric models to compare their directional forecast performance of Bitcoin returns (2011-2018) to artificial neural networks based on technical analysis. They show the ANN approach offers a superior predictive ability, and they remark on the existence of nonlinearities in the BTC/USD return series. Atsalakis et al. (2019) use a machine learning approach based on neurofuzzy models for the forecasting of Bitcoin returns (2011-2017). They conclude that it is an efficient method to forecast Bitcoin movements. Gradojevic et al. (2021) use several machine learning models applied to data sampled at hourly and daily frequencies to predict Bitcoin returns (2018-2019). They find the random forest model to be the most accurate at predicting Bitcoins. Chen et al. (2021) use two machine learning models fed with economic and technological variables (2011-2017). They find that such determinants are more important than using the previous exchange rate for predicting the Bitcoin exchange rate.

The second stream of studies examines the spillovers between cryptocurrency markets and other markets. Symitsi and Chalvatzis (2018) use a VAR-BEKK-AGARCH specification to analyze the spillovers between Bitcoin and stock indexes of clean energy, fossil fuel energy, and technology companies (2011-2018); they note bidirectional asymmetric shock spillovers between Bitcoin and stock indices. Bouri et al. (2018) use a STVAR-BTGARCH specification to study the spillovers between Bitcoin and stocks, commodities, currencies, and bonds in bearish and bullish market conditions 
(2010-2017); they note that Bitcoin returns are particularly related to commodities. Wang et al. (2019) use an MVQM-CAViaR model to examine the risk spillover effects of EPU and VIX indexes on Bitcoin (2010-2018); they find that the risk of Bitcoin price is independent of the changes of EPU but is related to volatility information. Gillaizeau et al. (2019) use the Diebold and Yilmaz (2012) spillover approach to estimate returns and high-low historical volatility spillovers among five currencies (USD, AUD, CAD, EUR, and GBP) quoted against Bitcoin. They note that the connectedness through volatility spillovers between BTC/USD and BTC/EUR matters most. Clearly, the USD/EUR seems to be the most influential FX pair on Bitcoins. Cajner et al. (2020) use GARCH specifications (TGARCH, GJR-GARCH, EGARCH) to study volatility spillovers from the FOMC Federal Fund target rate and QE policy announcements (2013-2017) to 58 digital assets. They find significant evidence of volatility spillovers from US monetary policy announcements to digital assets. Lyocsa et al. (2020) use the HAR model to study if the news announcements affect the volatility of Bitcoins (2013-2018). They find little evidence that the volatility of Bitcoins is influenced by most scheduled US macroeconomic news announcements, including monetary policy announcements. Other studies discuss spillovers among returns and volatility across cryptocurrencies to examine their level of integration using alternative approaches (transfer entropy, forecast error variance, bivariate copula, tail-risk interconnectedness, etc.) and mostly confirming the predominant role of the Bitcoin market among its peers (Huynh et al. 2020; Ji et al. 2021; Xu et al. 2021, etc.).

To the best of our knowledge, none of the existing studies investigate spillovers between Fed Funds rates and Bitcoin price returns; none of them explore the threshold or the higher-order effect between both variables. More generally, none of them focus particularly on the role played by Fed Funds rates. This research tries to fulfill the gap.

\section{Methodology}

\subsection{Linear regression models}

Prior to the spillover analysis between Bitcoins and the five other financial assets, we investigate the linear relation between the price log-returns of Bitcoin $y$ and other assets $x$ with the following multi-variable and multi-lag general specification:

$$
y_{t}=\delta_{0}+\sum_{l=0}^{L} \sum_{i=1}^{N} \delta_{i}^{l} x_{i t-l}+u_{t}
$$

where $i=1,2 \ldots, N$ assets represent all the financial assets considered in the study, which are measured in units of US dollars at a daily frequency over $t=1,2 \ldots, T$ trading days with lag $L$; in practice, $N$ is set to 5 assets and $L$ is set to a maximum of 10 days. $x_{i t-l}$ denotes the predictors of the dependent variable $y_{t}$, and $\delta_{i}^{l}$ is its coefficient at lag $l$; all assets are expressed in logarithmic returns. 


\subsection{Threshold regression models}

We pursue the investigation by determining the potential existence of a nonlinear relation between Bitcoin $y$ and the Fed Funds rate $x_{N}$ given the presence of other financial assets $x_{1}, x_{2} \ldots, x_{N-1}$ with the following threshold polynomial general specification:

$$
y_{t}=\delta_{0}+\sum_{i=1}^{N-1} \delta_{i} x_{i t}+\sum_{q=1}^{Q} \beta_{q}\left(\bar{x}_{N t}-\gamma\right)_{ \pm}^{q}+u_{t}
$$

where $\gamma$ stands for the threshold parameter and $x_{N}$ is its associated predictor. This nonlinear regression model is a nonconvex and nonsmooth function of the threshold parameter. The optimization method is based on a grid search approach and uses bootstrap simultaneous confidence bands (Son and Fong 2021).

The $x_{i}$ denote the $N-1$ additional predictors for $i=1,2, \ldots, N-1$. The $q=$ $1,2 \ldots, Q$ denote the $q$ th order of $\left(x_{N t}-\gamma\right)_{ \pm}^{q}$ with coefficients $\beta_{P}$; in practice, $Q$ is set equal to 3 and $\mathrm{N}$ equal to 5. $\left(x_{N t}-\gamma\right)_{+}=x_{N t}-\gamma$ if $x_{N t}>\gamma$ and 0 otherwise, and $\left(x_{N t}-\gamma\right)_{-}=x_{N t}-\gamma$ if $x_{N t} \leq \gamma$ and 0 otherwise. $\bar{x}_{N t}$ corresponds to the monthly average of the variable of interest, namely, the Fed Funds rate $x_{N t}$. The choice of computing a monthly variable to replace the real variable is motivated by the observation that the Fed rate log-returns are most of the time equal to zero; in the current sample, $81 \%$ of the time. Therefore, a standard OLS approach should on average produce an estimate of zero for the Fed rate, while in reality, its influence is far from null.

These equations complement Model 1, which misses nonlinear effects by construction. To that end, Model 2 combines threshold effects with higher-order effects to capture the nonlinearity among variables of interest.

\subsection{Directional spillover model}

This paper employs the VAR-based spillover measure from Diebold and Yilmaz (2009, 2012, 2014) on log-returns across the set of six assets. Diebold and Yilmaz (2009) introduce a spillover measure based on forecast error variance decompositions from vector autoregressions. Variance decompositions quantify how much of the $n$-stepahead forecast error variance of some variable $i$ is due to innovations in variable $j$. Diebold and Yilmaz (2012) extend this methodology by using a generalized vector autoregressive framework explicitly measuring the directional spillovers received by asset $i$ from all other assets $j$. While this generalized approach allows shocks to be correlated instead of orthogonalizing them, it accounts for them by using the historically observed distribution of the errors. As a consequence of not being orthogonalized, the sum of contributions to the variance of forecast error is no longer equal to one. Diebold and Yilmaz (2014) develop a measure of connectedness through variance decomposition by assessing shares of forecast error variation in various markets due to shocks arising elsewhere. Hence, the forecast error variance of a given variable $i$ is decomposed into parts attributed to the various variables $j$ in the system. Let's assume 
a $p$ th-order covariance stationary $N$-variable VAR specification:

$$
y_{t}=\sum_{l=1}^{p} \Phi_{l} y_{t-l}+u_{t}
$$

where $y_{t}$ is a $N \times 1$ vector of log-returns, $\Phi_{j}$ are $N \times N$ coefficient matrices and $u_{t} \hookrightarrow N\left(0, \sum_{u}\right)$ contains the error terms with covariance matrix $\Sigma_{u}$. The H-stepahead generalized forecast error variance decomposition for the $i$ th variable is given by (see Koop et al. 1996; Pesaran and Shin 1998; Diebold and Yilmaz 2012):

$$
\vartheta_{i \leftarrow j}^{(H)}=\frac{\sigma_{j j}^{-1} \sum_{h=0}^{H-1}\left(e_{i}^{\prime} A_{h} \Sigma_{u} e_{j}\right)^{2}}{\sum_{h=0}^{H-1} e_{i}^{\prime} A_{h} \Sigma_{u} A_{h}^{\prime} e_{i}}
$$

where for $i, j=1, \ldots, N$, the standard deviation $\sigma_{j j}$ of the error term $u$ is the $j$ th diagonal element of $\Sigma_{u}, e_{i}$ is a selection vector with its $i$ th element equal to 1 and 0 otherwise. The $A_{h}$ coefficient matrices, of the infinite order moving average representation of the VAR, obey a recursion of the following form: $A_{h}=\Phi_{1} A_{h-1}+$ $\Phi_{2} A_{h-2}+\cdots+\Phi_{p} A_{h-p}$ for $h=1,2, \ldots$ with $A_{0}$ is an $N \times d$ identity matrix and $A_{h}=0$ for $h<0$.

$\vartheta_{i \leftarrow j}^{(H)}$ expresses the variance contribution of variable $j$ to variable $i$. Variance decompositions allow splitting the forecast error variances of each variable into parts that are attributable to several system shocks, while generalized forecast error variance decomposition has the benefit of order invariance since it produces variance decompositions invariant to ordering. Each entry of the variance decomposition matrix is normalized to ensure by construction the row sum to be unity: $\Theta_{i \leftarrow j}^{(H)}=$ $100 \times\left(\vartheta_{i \leftarrow j}^{(H)} / \sum_{j=1}^{d} \vartheta_{i \leftarrow j}^{(H)}\right) \%$.

$\Theta_{i \leftarrow j}^{(H)}$ is a measure of pairwise spillover from variable $j$ to variable $i$ at horizon $H$. It is a directional measure because in general, $\Theta_{i \leftarrow j}^{(H)} \neq \Theta_{j \leftarrow i}^{(H)}$.

Diebold and Yilmaz $(2012,2014)$ define several quantities to characterize spillover effects. The proportion of the H-step ahead of the $i$ th asset that can be attributed to its own variance shares is denoted $O_{i \leftarrow i}^{(H)}$.

$$
O_{i \leftarrow i}^{(H)}=\Theta_{i \leftarrow i}^{(H)}
$$

The total spillovers from the system to asset $i$ are given by $S_{i \leftarrow \bullet}^{(H)}$, which is referred to as the "FROM" all others.

$$
S_{i \leftarrow \bullet}^{(H)}=\sum_{j=1, j \neq i}^{d} \Theta_{i \leftarrow j}^{(H)} .
$$


The total spillovers from asset $i$ to the system are measured by $S_{\bullet \leftarrow i}^{(H)}$, which is referred to as the "TO" all others.

$$
S_{\bullet \leftarrow i}^{(H)}=\sum_{j=1, j \neq i}^{d} \Theta_{j \leftarrow i}^{(H)} .
$$

It follows by construction: $O_{i \leftarrow i}^{(H)}+S_{i \leftarrow \bullet}^{(H)}=100 \%$.

The "NET" spillover from asset $i$ to all other assets $j$ summarizes information about how much in net terms each asset contributes to other assets. It is the difference between shocks transmitted TO and shocks received FROM all other assets:

$$
S_{i}^{(H)}=S_{\bullet \leftarrow i}^{(H)}-S_{i \leftarrow \bullet}^{(H)} .
$$

The "NET pairwise" spillovers between assets $i$ and $j$ are simply the difference between shocks transmitted from asset $i$ to $j$ and shocks transmitted from $j$ to $i$ :

$$
S_{i j}^{(H)}=\Theta_{j \leftarrow i}^{(H)}-\Theta_{i \leftarrow j}^{(H)} .
$$

The aggregate spillover among assets is:

$$
S^{(H)}=\frac{1}{d} \sum_{i=1}^{d} S_{i \leftarrow \bullet}^{(H)}
$$

where $S^{(H)}$ denotes the total log-returns spillover index and $O^{(H)}$ denotes the aggregate own variable effect. It measures the contribution of spillover shocks across the six assets to the total forecast error variance. Following Diebold and Yilmaz (2012), the results are based on vector autoregressions of order 4 and generalized variance decompositions of 10-day-ahead log-returns forecast errors. The choices of the rolling window are set to 200-day rolling samples.

\section{Data description}

\subsection{Data set}

The financial data set is downloaded from the St Louis Fed data center (FRED) and consists of representative assets spanning the period from January 1, 2015, to February 28,2021 . These financial data have a daily frequency to account for the federal funds rate changes, and all the series are transformed into log-returns.

- BTC/USD Coinbase Bitcoin (US Dollars; RBITCOIN)

- S\&P 500 (RSPX)

- Gold Fixing Price (London Bullion Market, US Dollars; RGOLD)

- US Federal Funds Rate (RFF)

- 10-year US Treasury Constant Maturity Rate (RDGS10)

- US/Euro Foreign Exchange Rate (US Dollars; RFX) 
The BTC/USD pair is expressed in US Dollars and retrieved from FRED, ${ }^{6}$ which states that the original data comes from the Coinbase platform. ${ }^{7}$

The choice of Coinbase trading platform is motivated because it's the most prominent crypto exchange in North America with 73 million verified users although, in terms of an annual volume of exchange in USD, Coinbase comes second after Binance. Coinbase reported ${ }^{8}$ that Bitcoin represented $70 \%$ of the assets on its spot trading platform, and the value of crypto-assets on this platform represented $11.1 \%$ of the total market capitalization of global crypto-assets.

The choice of Bitcoin is motivated because its total market capitalization ranks ${ }^{9}$ first with $\$ 962$ billion, far behind Ethereum ( $\$ 481$ billion), and leaves behind other cryptoassets with capitalizations below $\$ 83$ billion. The Coinbase $24 \mathrm{~h}$ trading volume is around $\$ 4.55$ billion, ranked 3rd among the largest exchanges with approximately a $4.75 \%$ market share. The Coinbase $24 \mathrm{~h}$ trading volume is around $\$ 850$ million, ranked 1 st in BTC/USD and 4th when considering both BTC/USD and BTC/USDT markets. The choice of the BTC/USD exchange rate is motivated because it has been historically the first cryptocurrency pair and still remains the first quote among crypto-assets. The BTC/USD pair is directly available and downloaded at a daily frequency from FRED. The BTC/USD pair is quoted $24 \mathrm{~h}$ per day in several exchanges like fiat currencies. Generally, each trading day for cryptocurrencies is defined as beginning at $12.00 \mathrm{AM}$ and ending at 11.59 PM (Coordinated Universal Time) in open, high, low, and close prices. Moreover, the existing quotes are most of the time available at the daily frequency, ${ }^{10}$ but still, they exist at the hourly frequency. ${ }^{11}$ Data providers could compute the daily quotes by averaging intraday book quotes of a particular exchange or even by averaging quotes from many exchanges. But in the case of FRED, the BTC/USD pair is available at the closing price as of 5.00 PM Pacific Standard Time (PST) on a 7 days a week basis. Notice that cryptocurrency markets lack a consolidated source of data and information.

To gauge whether the spillover from the Fed Funds rates to the Bitcoin prices are affected by other relevant financial variables, we run supplementary tests with one measure of aggregate risk (VIX Index; daily data; CBOE) and another representative commodity (West Texas Intermediate (WTI), Cushing, Oklahoma; daily data; Energy Information Administration). These influential assets are gathered with the set of the six selected assets in a nonreported test to save space. Moreover, to investigate the existence of macrofinancial spillovers to Bitcoin, a set of macroeconomic variables ${ }^{12}$ is downloaded from St Louis Fed. The macroeconomic data are sampled at a monthly frequency.

- Nominal FRB Dollar (RFRB)

- Weekly Initial Claim (RCLAIM)

\footnotetext{
6 fred.stlouisfed.org/series/CBBTCUSD.

7 www.coinbase.com/fr/price/bitcoin.

8 www.sec.gov/Archives/edgar/data/1679788/000162828021003168/coinbaseglobalincs-1.htm.

9 coinranking.com.

10 coinmarketcap.com.

11 cryptodatadownload.com.

12 We are grateful to the anonymous reviewer for this suggestion.
} 
- Industrial Production Index (RINDPRO)

- Total Nonfarm Payroll (RPAYROLL)

- Consumer Price Index (RCPI)

The nominal FRB dollar reflects the trade-weighted US dollar exchange index published by the Board of Governors of the US FED, which measures the value of the United States dollar relative to other world currencies and proxies the return of the currency market. The weekly initial claim, filed by an unemployed individual, after a separation from an employer, determines eligibility for the unemployment insurance program. The frequency available is weekly, but it is converted into monthly frequency by averaging the 4 weekly observations. The industrial production index measures real output for all facilities located in the United States. The total Nonfarm Payroll measures the number of US workers in the economy (excluding proprietors, private household employees, unpaid volunteers, farm employees, and the unincorporated self-employed). It accounts for approximately $80 \%$ of the workers who contribute to gross domestic product (GDP). The Consumer Price Index for All Urban Consumers measures the average monthly change in the price for goods and services (Less Food and Energy) paid by urban consumers. It also represents the buying habits of urban consumers and accounts for approximately $88 \%$ of the total population.

All financial and macroeconomic time series are transformed into log-returns (RBTICOIN, RSPX, RFX, RFF, RDGS10, RGOLD; RVIX, RWTI; RFRB, RCLAIM, RINDPRO, RPAYROLL, RCPI). The empirical tests are implemented on Software R 4.0.3. ${ }^{13}$

\subsection{Descriptive statistics}

Table 1 summarizes the descriptive statistics (Panel A: financial variables; Panel B: macroeconomic variables). Interestingly, both RBITCOIN and RFF are mostly negatively skewed and have by far the highest kurtosis. Figure 1 focuses on the price dynamics of both Bitcoin and Fed Funds rates. We note a striking feature in the pattern of both variables: they evolve in opposite direction from March 2020. At that time, two unscheduled FOMC meetings occurred, driving subsequent rates cut on March 3 by $-50 \mathrm{bp}$ and March 16 by $-100 \mathrm{bp}$, lowering the nominal short-term interest rates in the range of $0-0.25 \%$. Given the magnitude of the cut, we would expect spillover effects on several financial assets, among which Bitcoin.

One can also visually identify two/three clear peaks/through, the first in 2017-12, the second (smaller) in 2019-07, and the last one (larger) from March 2020.

Table 1 (Panels A and B) also exhibits the ADF (Dickey and Fuller, 1979) univariate unit root test. This test confirms the absence of unit roots in the time series.

Table 1 (Panel C) displays a breakpoint analysis to check for visual nonlinearities in the Bitcoin log-returns time series.

The Bai and Perron (1998, 2003) test detects breakpoints (2016-01-15, 2017-01-11, 2017-12-18, 2018-12-14, 2020-03-12). It seems that Bitcoins dynamics have been mainly changing in 2020, although visual inspection may add 2019 to 2020.

\footnotetext{
13 I acknowledge the use of the following libraries: chngpt; corrplot; dyn; github.com/gabauerdavid; github.com/jomopo; lmtest; roll; rollRegres; rugarch; strucchange; tseries; urca; xdcclarge.
} 


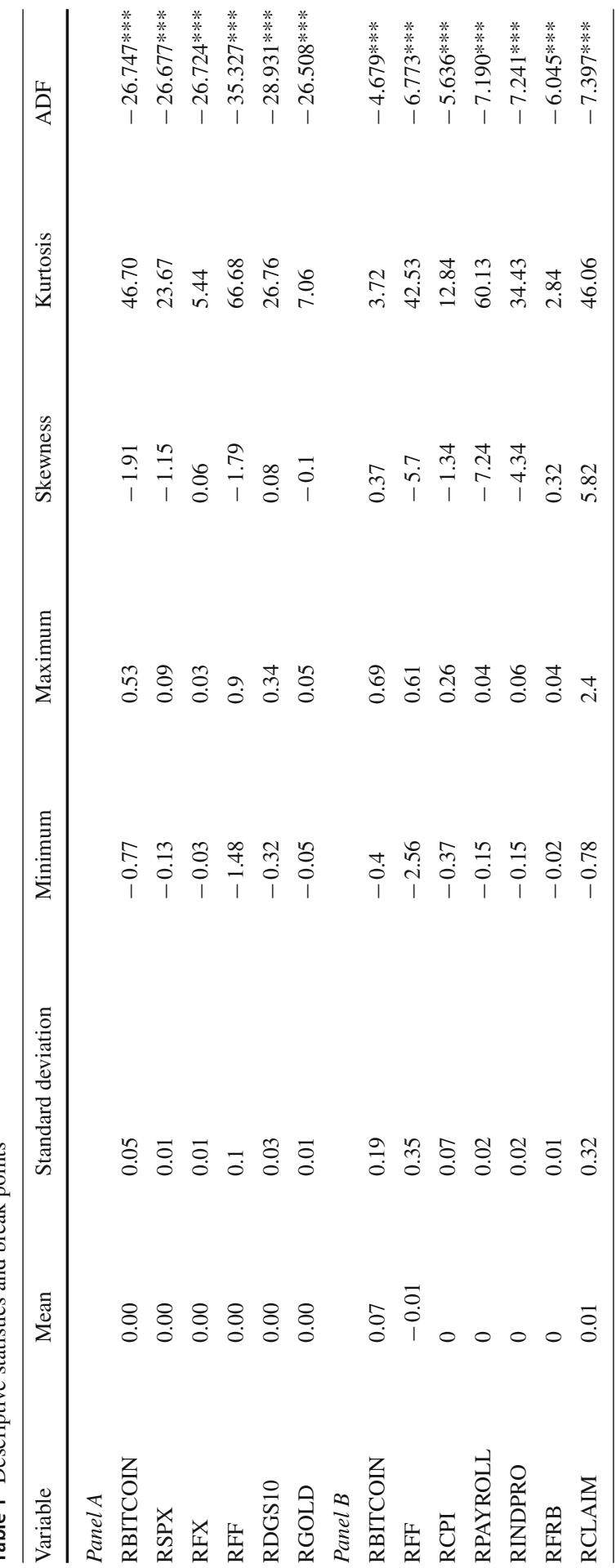




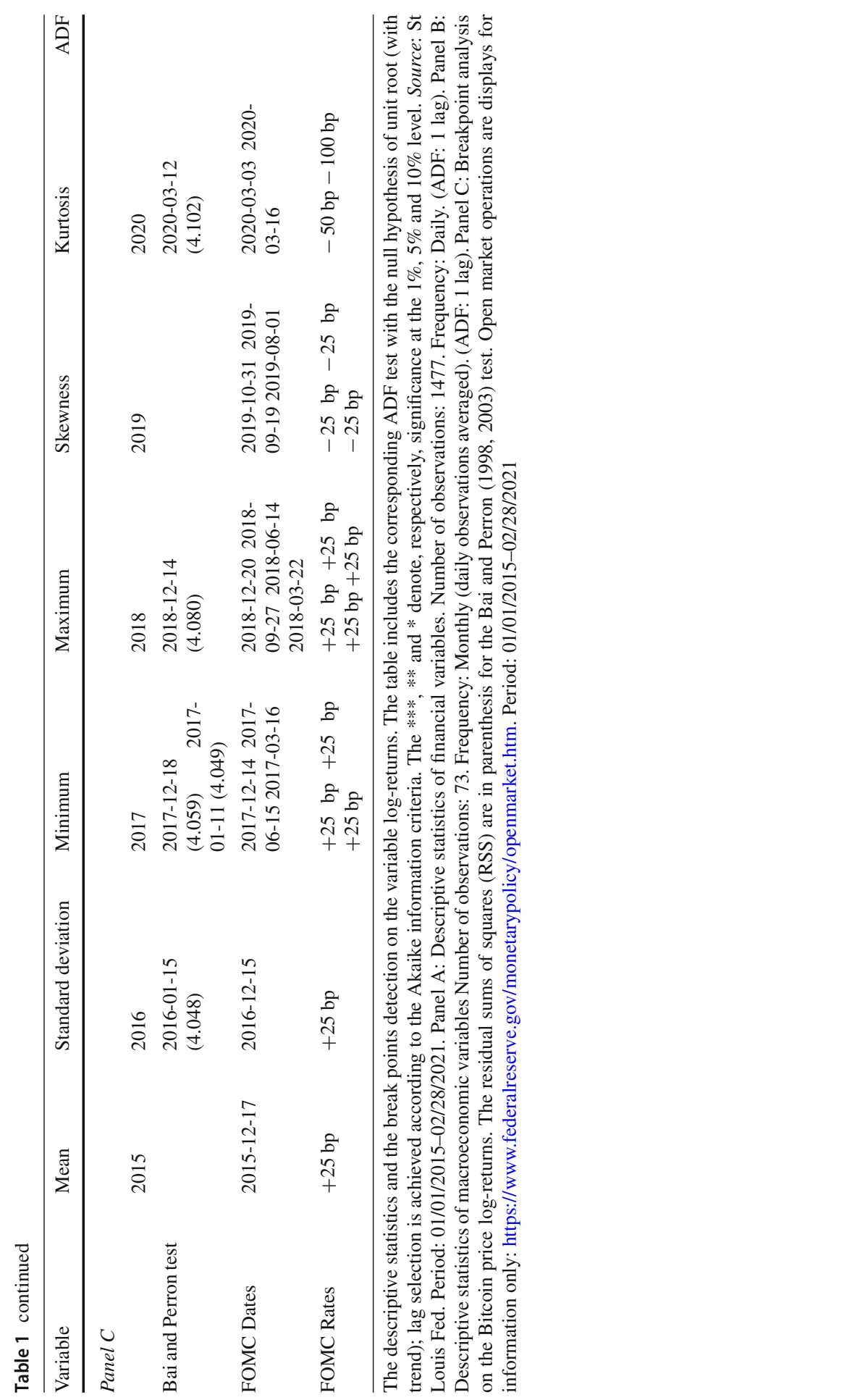


Table 2 Sample and DCC-GARCH correlation matrix

\begin{tabular}{lllllll}
\hline & RBITCOIN & RSPX & RFX & RFF & RDGS10 & RGOLD \\
\hline RBITCOIN & 1 & 0.14 & 0.01 & -0.00 & 0.02 & 0.12 \\
\multirow{2}{*}{ RSPX } & 1 & 0.08594 & 0.17521 & -0.02348 & 0.03283 & 0.1800 \\
& 0.14 & 1 & -0.01 & 0.12 & 0.44 & 0.09 \\
RFX & 0.08594 & 1 & 0.003113 & 0.00951 & 0.19012 & -0.04980 \\
& 0.01 & -0.01 & 1 & -0.02 & -0.09 & 0.39 \\
RFF & 0.17521 & 0.003113 & 1 & -0.03223 & -0.00288 & 0.45699 \\
& -0.00 & 0.12 & -0.02 & 1 & 0.12 & 0.03 \\
RDGS10 & 0.02 & 0.00951 & -0.03223 & 1 & 0.05622 & 0.01641 \\
& 0.03283 & 0.19012 & -0.00288 & 0.05622 & 1 & -0.13 \\
RGOLD & 0.12 & 0.09 & 0.39 & 0.03 & -0.13 & 1 \\
& 0.18000 & -0.04980 & 0.45699 & 0.01641 & -0.24500 & 1 \\
\hline
\end{tabular}

The correlation matrix of the six financial variables. There are two measures of correlation: the Pearson sample correlation (top cell) and the DCC-GARCH(1,1) time-varying correlation (bottom cell). Period: 01/01/2015-02/28/2021

Table 2 exhibits the correlation matrix for the Pearson and DCC-GARCH( 1,1$)$ coefficients. RSPX (0.15) and RGOLD (0.12) exhibit the highest positive correlation with RBITCOIN. Figure 2 highlights the visual correlation matrix (left plot), where Bitcoin appears mainly correlated with S\&P 500, while Fed Funds rates appear logically correlated with both S\&P 500 and DGS10. RBITCOIN is positively correlated with all assets, except RFF with an almost zero average correlation (-0.00); the time-varying correlation as measured by a DCC-GARCH specification indicates a slightly negative value (-0.02). Figure 2 also highlights the scaled-based correlations between the RFF
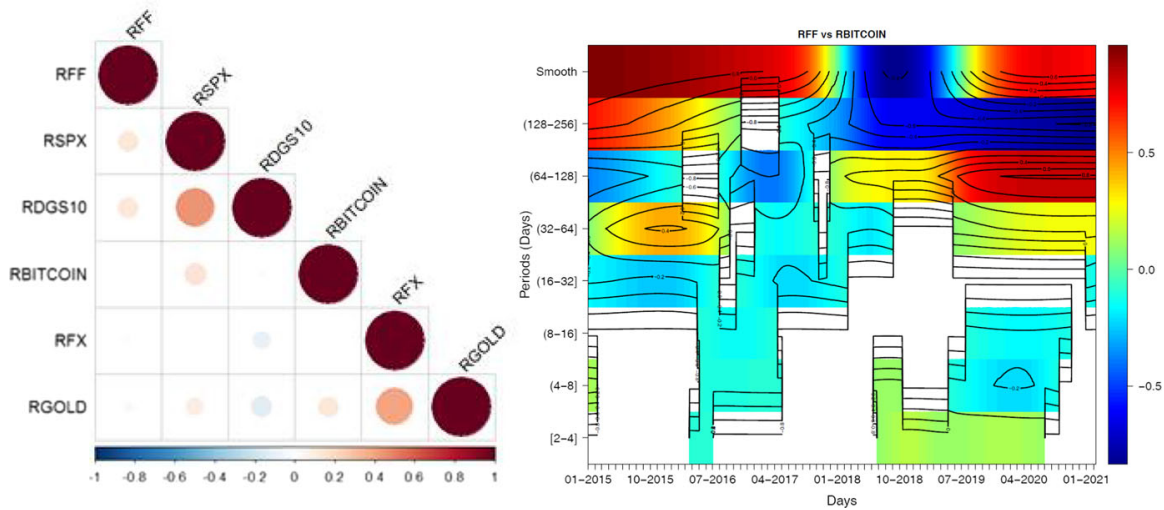

Fig. 2 Correlation plot and heat map. Note: Figure 2 displays the daily correlation plot (left) between the price log-returns of the six variables and the heat map (right) between Fed Funds rates and Bitcoin price returns. The heat map displays the scale-based correlation between RFF and RBITCOIN; the white color indicates a correlation that is not statistically significant. Period: 01/01/2015-02/28/2021 
Table 3 Linear regression models

\begin{tabular}{|c|c|c|c|c|}
\hline & Model 1a & Model 1b & Model 1c & Model 1d \\
\hline Intercept $\partial_{0}$ & $\begin{array}{l}0.0031703 * * \\
(0.0014009)\end{array}$ & $\begin{array}{l}0.0037392 * * * \\
(0.0012884)\end{array}$ & $\begin{array}{l}0.0033469 * * * \\
(0.0012399)\end{array}$ & $\begin{array}{l}0.0034030 \text { *** } \\
(0.0012401)\end{array}$ \\
\hline $\operatorname{RSPX} \partial_{1}$ & $\begin{array}{l}0.6060827^{* *} \\
(0.2912800)\end{array}$ & $\begin{array}{l}0.5574456^{* *} \\
(0.2242168)\end{array}$ & $\begin{array}{l}0.6006998 * * * \\
(0.2202253)\end{array}$ & $\begin{array}{l}0.5953440 \text { *** } \\
(0.2227042)\end{array}$ \\
\hline RFX $\partial_{2}$ & $\begin{array}{l}-0.4037381 \\
(0.4351022)\end{array}$ & & & \\
\hline RDGS10 $\partial_{3}$ & $\begin{array}{l}-0.0353543 \\
(0.0667635)\end{array}$ & & & \\
\hline RGOLD $\partial_{4}$ & $\begin{array}{l}0.6692641 * * * \\
(0.2273104)\end{array}$ & $\begin{array}{l}0.6692160 \text { *** } \\
(0.2101322)\end{array}$ & $\begin{array}{l}0.5993270 * * * \\
(0.1957786)\end{array}$ & $\begin{array}{l}0.5949320 \text { *** } \\
(0.1956197)\end{array}$ \\
\hline RFF $\partial_{5}$ & $\begin{array}{l}-0.0098381 \\
(0.0115813)\end{array}$ & & & \\
\hline $\operatorname{RFX}(-1) \partial_{2}$ & & $\begin{array}{l}-0.3980150^{*} \\
(0.2249355)\end{array}$ & $\begin{array}{l}-0.4525675^{* * *} \\
(0.2235664)\end{array}$ & $\begin{array}{l}-0.4196929 * \\
(0.2240820)\end{array}$ \\
\hline $\operatorname{RDGS10(-1)} \partial_{3}$ & & $\begin{array}{l}0.0605508^{*} \\
(0.0361546)\end{array}$ & $\begin{array}{l}0.0637524 * \\
(0.0349502)\end{array}$ & $\begin{array}{l}0.0618060^{*} \\
(0.0356167)\end{array}$ \\
\hline $\mathrm{RFF}(-1) \partial_{4}^{1}$ & & $\begin{array}{l}-0.0098046 \\
(0.0105900)\end{array}$ & & $\begin{array}{l}-0.0166002 \\
(0.0111248)\end{array}$ \\
\hline $\operatorname{RFF}(-2) \partial_{4}^{2}$ & & & & $\begin{array}{l}-0.0209548^{*} \\
(0.0118617)\end{array}$ \\
\hline $\operatorname{RFF}(-3) \partial_{4}^{3}$ & & & & $\begin{array}{l}-0.0219103 \\
(0.0169909)\end{array}$ \\
\hline $\operatorname{RFF}(-5) \partial_{4}^{5}$ & & & $\begin{array}{l}-0.0178414 * \\
(0.0105934)\end{array}$ & \\
\hline$R^{2}$ & 0.03143 & 0.03757 & 0.04048 & 0.04245 \\
\hline
\end{tabular}

The results for the linear regression models. Several configurations are tested but only most relevant are reported in this table. Heteroscedasticity-consistent estimation of the covariance matrix of the coefficient estimates is computed. AIC (-4530.926; - 4770.445; - 4887.607; - 4883.646) and BIC (-4493.842; -4733.366 ; - 4839.945; - 4846.586) information ratios are used to select lag lengths in time series regression models $1 \mathrm{a}, 1 \mathrm{~b}, 1 \mathrm{c}$, and $1 \mathrm{~d}$; Model 1a appears the most parsimonious. The $* * *, * *$ and $*$ denote, respectively, significance at the $1 \%, 5 \%$ and $10 \%$ level. Period: $01 / 01 / 2015-02 / 28 / 2021$

and RBITCOIN (right plot). It shows that since 2018, their level of correlation has become increasingly negative and statistically significant over the long run (128-256 days).

\section{Empirical findings}

\subsection{Results}




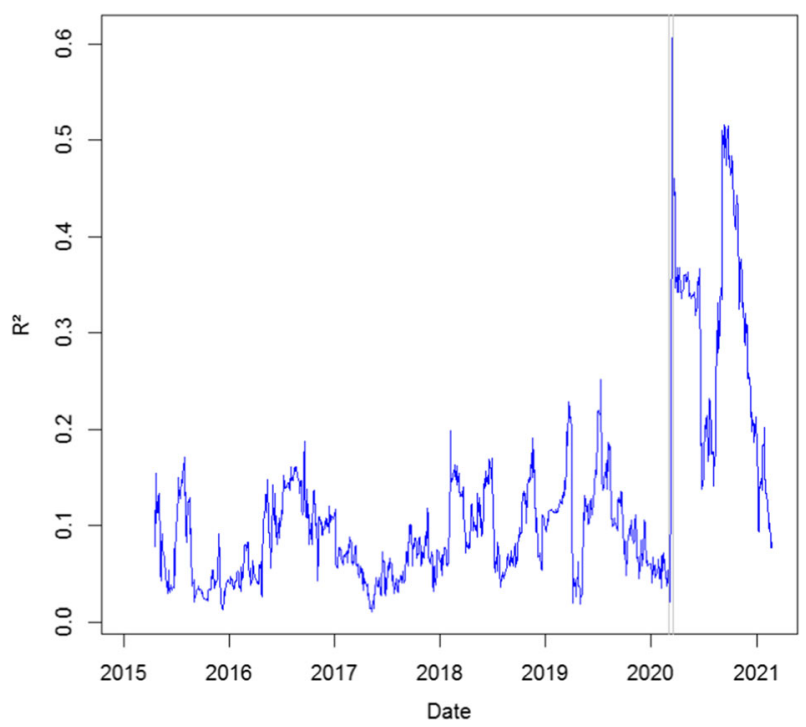

Fig. $3 R^{2}$ from rolling OLS regression. Note: Figure 3 displays the rolling $R$-squared of the Model 1 . The two gray vertical lines correspond exactly to March 3 and 16, 2020 when the Fed Fund rates were cut, respectively, by $50 \mathrm{bp}$ and $100 \mathrm{bp}$. Period: 01/01/2015-02/28/2021

Table 3 exhibits the results from Model 1 that relates Bitcoin log-returns with the set of representative financial variables. Several settings are tested with contemporaneous and lagged (dependent, explanatory) variables, but only four models (1a, 1b, 1c, and 1d) are exposed for their relevance according to information criteria (AIC and BIC). Model 1a exhibits the contemporaneous relation among variables where only RSPX and RGOLD are statistically significant. Model $1 \mathrm{~b}$ imposes a 1-day lag structure on the three other explanatory variables (RFX, RDGS10, RFF); only RFX(-1) and RDGS10(-1) are statistically significant, but not RFF(-1). Model 1c checks on which day lag the RFF variable becomes statistically significant for Model 1b; only lag 5 appears statistically significant. Model 1d imposes a 5-day lag effect on RFF and finds statistical significance on the RFF variable when the first three lags are retained. All RFF lagged coefficients are negative. However, AIC and BIC show that Model 1a remains the most parsimonious. The weak $R^{2}$ regardless of the combination shows that Bitcoin does not seem to be strongly affected on a day-by-day basis by other markets. However, it could be the case on a temporary basis. To that end, a rolling regression is implemented on Model 1a to display the $R^{2}$ in Fig. 3. Interestingly, the $R^{2}$ peaks to its highest level ever $(60.60 \%)$ on $2020-03-13$, followed by $2020-03-12$, 2020-03-17, and 2020-03-16, which corresponds to the week (see FOMC dates in Table 2) of the -150 basis points declining Fed Funds rates; the following 140 dates occurred from March to December 2020.

Put together, these findings show that i) RSPX and RGOLD are the most influential markets on RBITCOIN, ii) RFF has a weak delayed impact on RBITCOIN, and iii) RFF has a stronger indirect influence on RBITCOIN through other markets, as evidenced by the rolling $R^{2}$. 
Table 4 exhibits the results from Model 2, which extends the previous analysis where RFF shows no contemporaneous linear relation with RBITCOIN. In this framework, the monthly average value of RFF, denoted by $\overline{R F F}$, replaces the variable RFF. The reason comes from the observation that most of the time the RFF value is zero, which explains mostly why under Model 1, RFF is not significant and even dropped in most of the studies, as reported in the relevant literature. However, given that Fed Funds

Table 4 Threshold regression models

\begin{tabular}{|c|c|c|c|c|}
\hline & Model 2a & Model 2b & Model 2c & Model 2d \\
\hline Intercept $\partial_{0}$ & $\begin{array}{l}1.561257 \mathrm{e}-03 \\
(3.806083 \mathrm{e}-03)\end{array}$ & $\begin{array}{l}2.397536 \mathrm{e}-03 \\
(2.448464 \mathrm{e}-03)\end{array}$ & $\begin{array}{l}4.165276 \mathrm{e}-03 \\
(2.563575 \mathrm{e}-03)\end{array}$ & $\begin{array}{l}5.839121 \mathrm{e}-03 * * \\
(2.974320 \mathrm{e}-03)\end{array}$ \\
\hline $\operatorname{RSPX} \partial_{1}$ & $\begin{array}{l}5.972525 \mathrm{e}-01 * * \\
(2.592583 \mathrm{e}-01)\end{array}$ & $\begin{array}{l}6.017768 \mathrm{e}-01 * * \\
(2.602484 \mathrm{e}-01)\end{array}$ & $\begin{array}{l}5.851239 \mathrm{e}-01 * * \\
(2.622226 \mathrm{e}-01)\end{array}$ & $\begin{array}{l}6.012204 \mathrm{e}-01 * * \\
(2.605143 \mathrm{e}-01)\end{array}$ \\
\hline RFX $\partial_{2}$ & $\begin{array}{l}-4.298625 \mathrm{e}-01 \\
(4.162414 \mathrm{e}-01)\end{array}$ & $\begin{array}{l}-4.029926 \mathrm{e}-01 \\
(4.258805 \mathrm{e}-01)\end{array}$ & $\begin{array}{l}-4.358011 \mathrm{e}-01 \\
(4.092755 \mathrm{e}-01)\end{array}$ & $\begin{array}{l}-4.200655 \mathrm{e}-01 \\
(4.276817 \mathrm{e}-01)\end{array}$ \\
\hline RDGS $10 \partial_{3}$ & $\begin{array}{l}-3.798150 \mathrm{e}-02 \\
(6.045582 \mathrm{e}-02)\end{array}$ & $\begin{array}{l}-4.104686 \mathrm{e}-02 \\
(6.237686 \mathrm{e}-02)\end{array}$ & $\begin{array}{l}-3.494736 \mathrm{e}-02 \\
(6.057562 \mathrm{e}-02)\end{array}$ & $\begin{array}{l}-4.259983 \mathrm{e}-02 \\
(6.303396 \mathrm{e}-02)\end{array}$ \\
\hline RGOLD $\partial_{4}$ & $\begin{array}{l}6.687538 \mathrm{e}-01 * * * \\
(2.177698 \mathrm{e}-01)\end{array}$ & $\begin{array}{l}6.676277 \mathrm{e}-01 * * * \\
(2.236287 \mathrm{e}-01)\end{array}$ & $\begin{array}{l}6.645394 \mathrm{e}-01 * * * \\
(2.180740 \mathrm{e}-01)\end{array}$ & $\begin{array}{l}6.773730 \mathrm{e}-01 * * * \\
(2.235468 \mathrm{e}-01)\end{array}$ \\
\hline$\overline{R F F} \beta_{1}+$ & $\begin{array}{l}2.160163 \mathrm{e}+01 * \\
(1.123772 \mathrm{e}+01)\end{array}$ & & $\begin{array}{l}-5.470924 \mathrm{e}+01 * * \\
(2.494562 \mathrm{e}+01)\end{array}$ & \\
\hline$\overline{R F F} \beta_{2}+$ & $\begin{array}{l}-1.041345 \mathrm{e}+04 * * \\
(5.184947 \mathrm{e}+03)\end{array}$ & & $\begin{array}{l}2.071179 \mathrm{e}+04 * * \\
(1.016914 \mathrm{e}+04)\end{array}$ & \\
\hline$\overline{R F F} \beta_{3}+$ & & & $\begin{array}{l}-1.902116 \mathrm{e}+06 \\
(2.897746 \mathrm{e}+06)\end{array}$ & \\
\hline$\overline{R F F} \beta_{1}-$ & & $\begin{array}{l}-6.739648 \mathrm{e}+00 \\
(5.118882 \mathrm{e}+00)\end{array}$ & & $\begin{array}{l}8.815746 \mathrm{e}+00 * \\
(4.904197 \mathrm{e}+00)\end{array}$ \\
\hline$\overline{R F F} \beta_{2}-$ & & $\begin{array}{l}-6.536575 \mathrm{e}+02 \\
(4.799779 \mathrm{e}+02)\end{array}$ & & $\begin{array}{l}1.991600 \mathrm{e}+03^{*} \\
(1.110298 \mathrm{e}+03)\end{array}$ \\
\hline$\overline{R F F} \beta_{3}-$ & & & & $\begin{array}{l}9.412896 \mathrm{e}+04 * \\
(5.400140 \mathrm{e}+04)\end{array}$ \\
\hline Threshold $\gamma$ & $\begin{array}{l}0.002599618 \\
(0.002605920)\end{array}$ & $\begin{array}{l}-0.001821724 \\
(0.001647250)\end{array}$ & $\begin{array}{l}-0.001821724 \\
(0.003553521)\end{array}$ & $\begin{array}{l}0.0031923846 * * * \\
(0.0005193565)\end{array}$ \\
\hline Lower CI & -0.007615589 & -0.001821724 & -0.011761159 & 0.0025996175 \\
\hline Upper CI & 0.002599618 & 0.004635495 & 0.002168644 & 0.0046354949 \\
\hline
\end{tabular}

Tables 5 and 6 present the results for the threshold regression models. Several configurations are tested but only most relevant are reported in this table. Heteroscedasticity-consistent estimation of the covariance matrix of the coefficient estimates is computed. Likelihood ratio tests are used to compare the goodness of fit of the models to evaluate the benefit to add a parameter to the simple model 1a. This null hypothesis to favor the simplest model 1a is rejected at 5\% significance level (Model 2b: Chi-squared 2.2983, $p$ value 0.0000; Model 2c: Chi-squared 7.9533, $p$ value 0.00480; Model 2d: Chi-squared 1.7617, $p$ value 0.000$)$ except, at $10 \%$ significance level, for Model 2a (Chi-squared 5.5968, $p$ value 0.06091$). \overline{R F F}$ denotes the monthly mean of $R F F$ variable. The $* * *, * *$ and $*$ denote, respectively, significance at the $1 \%, 5 \%$ and 10\% level. Period: 01/01/2015-02/28/2021 
rates are influential in reality, it is better to replace the current variable RFF by its monthly average because market participants take into consideration Fed monetary policy in one way or another.

$\overline{R F F}$ allows examining the potential contemporaneous nonlinear relation with RBITCOIN. Four models (2a, 2b, $2 \mathrm{c}$ and $2 \mathrm{~d}$ ) are exposed. Models $2 \mathrm{a}$ and $2 \mathrm{~b}$ test the presence of the threshold effect at order 2 when $\overline{R F F}$ is above its threshold $\gamma:\left(x_{N t}-\gamma\right)_{+}^{2}$ or below its threshold $\gamma:\left(x_{N t}-\gamma\right)_{-}^{2}$, respectively. Models $2 \mathrm{c}$ and $2 \mathrm{~d}$ test the presence of a threshold effect at order 3 when $\overline{R F F}$ is above its threshold $\gamma:\left(x_{N t}-\gamma\right)_{+}^{3}$ or below its threshold $\gamma:\left(x_{N t}-\gamma\right)_{-}^{3}$, respectively. Models 2a, 2c and 2d provide clear evidence of higher-order contemporaneous relations between $\overline{R F F}$ and RBITCOIN. When it is above its threshold, $\overline{R F F}$ is statistically significant at order 2 (Model 2a) but not at order 3 (Model 2c). When it is below its threshold, $\overline{R F F}$ is statistically significant at order 3 (Model 2d) but not at order 2 (Model 2b). In other words, the threshold effect exists for $\overline{R F F}$ when it is above its threshold at order 2 and below its threshold at order 3 . Note that the threshold parameter is statistically significant only for Model 2d, where all coefficients are positive.

Put together, these findings show that i) $\overline{R F F}$ influences RBITCOIN through threshold effects and higher-order effects, and ii) when $\overline{R F F}$ is below its threshold, it strongly, positively and significantly influences RBITCOIN.

Table 5 exhibits the results from the directional spillover (gross and net) model across the six daily financial variables from Eqs. 3 to 10. The total (nondirectional) spillover index appears in the lower right corner of the table (15.41\%) and is approximately the "Directional FROM others" column sum divided by the "Directional including own" row sum. Figure 4 displays the "total" spillover plot for the financial variables with

Table 5 Spillovers matrix with financial data

\begin{tabular}{lrrrrrrl}
\hline & \multicolumn{1}{c}{ RBITCOINRSPX RFX } & RFF & \multicolumn{2}{l}{ RDGS10RGOLDContribution FROM others } \\
\hline RBITCOIN & 94.89 & 2.13 & 0.38 & 0.37 & 0.38 & 1.86 & 5.11 \\
RSPX & 2.84 & 77.43 & 0.42 & 0.85 & 15.97 & 2.50 & 22.57 \\
RFX & 0.41 & 0.45 & 84.10 & 0.75 & 0.86 & 13.43 & 15.90 \\
RFF & 1.83 & 2.08 & 0.25 & 94.15 & 1.46 & 0.24 & 5.85 \\
RDGS10 & 0.73 & 16.29 & 0.58 & 1.34 & 78.16 & 2.89 & 21.84 \\
RGOLD & 1.01 & 1.48 & 12.38 & 0.51 & 5.81 & 78.81 & 21.19 \\
Contribution TO others & 6.82 & 22.43 & 14.01 & 3.81 & 24.48 & 20.92 & 92.47 \\
Directional including own & 101.70 & 99.85 & 98.11 & 97.97102 .64 & 99.72 & TSI: $15.41 \%$ \\
Net directional connectedness & 1.70 & $-0.15-1.89-2.03$ & 2.64 & -0.28 & \\
\hline
\end{tabular}

The results for the spillover directional model applied on financial data with daily frequency. The results are based on vector autoregressions (order 4) and generalized variance decompositions of 10-day ahead log-returns forecast errors; spillovers are estimated using 200-day rolling samples. The contributions to others and from others are the "TO" and "FROM" directional spillovers. The FROM minus TO differences corresponds to the Net spillovers. The Total Spillover Index (lower right corner) is the "FROM" column sum relative to the "Directional including own" row sum expressed as a percentage. Period: 01/01/201502/28/2021 
an observable peak that is near 50\% around March 2020. Concerning own variance shares, RBITCOIN (94.89) and RFF (94.15) have by far the highest level.

Regarding the gross directional spillovers "TO" others, Bitcoins and Fed Funds rates are the lowest transmitters of spillovers, with 6.82 for RBITCOIN and 3.81 for RFF. Figure 5 displays directional spillovers "TO" all others. It reveals that Bitcoins experienced a dramatic surge in spillovers to other assets from March 2020. The same applies to Fed Funds rates, but spillovers look very limited around March 2020.

Regarding the gross directional spillovers "FROM" others, Bitcoins and Fed Funds rates are also the lowest receivers of spillovers, with 5.11 for RBITCOIN and 5.85 for RFF. Figure 6 displays the directional spillovers "FROM" all others. It shows that all assets have been recipients of spillovers, although the surge looks sharper for Fed Funds rates and Bitcoins beginning in March 2020.

From the directional spillovers "FROM" and "TO", RSPX, RDGS10, and RGOLD have the same magnitude, while the RFX variable appears less influential.

Concerning the "Net" directional spillovers, the largest values are from both RDGS10 and RFF, and the lowest are from RSPX and RGOLD. All of them appear as quite low regardless of their sign. Figure 7 displays the "Net" Spillovers. It clearly shows that the "Net" directional spillovers mainly affect Bitcoins and Fed Funds rates from March 2020.

Figure 8 displays the "Net Pairwise" spillovers among the six variables to better investigate the relation between variable pairs. What is most striking is the pair "RBITCOIN-RFF." It experienced a dramatic surge from March 2020 until the end of 2020, despite an average value close to zero before the surge. It shows that the dramatic rise began exactly one week after the 100 bp cut on March 23, 2020 (2.49), and ended on January 7, 2021 (2.34), while the peak (4.58) occurred on November 9, 2020 .
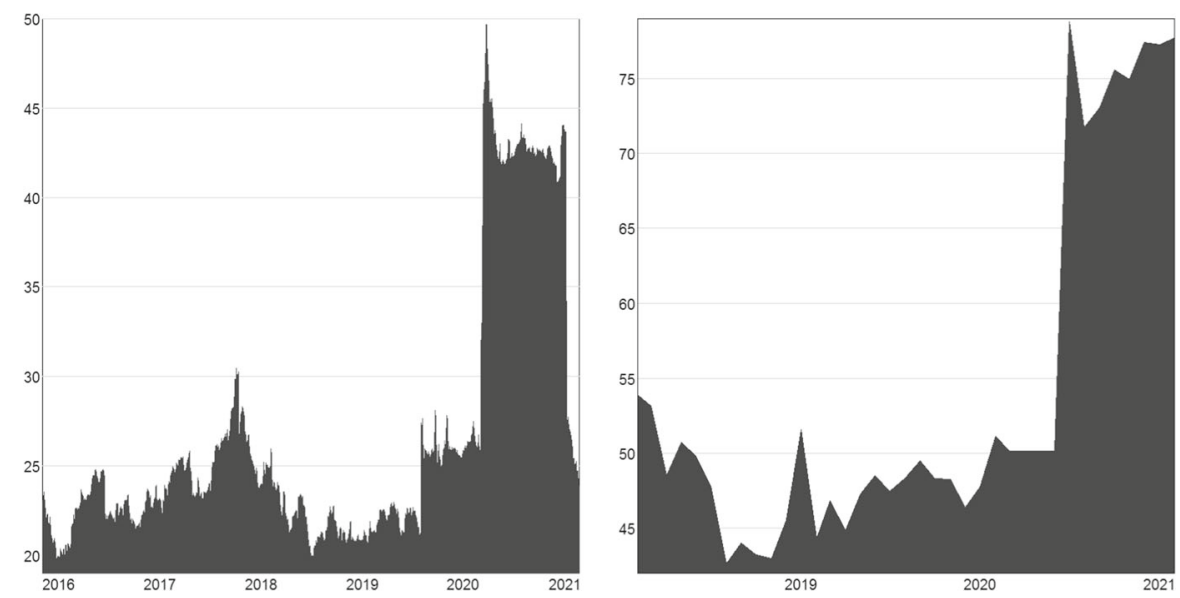

Fig. 4 Total financial and macroeconomic spillovers. Note: Figure 4 displays the total spillover index from Eq. 10. Left: Financial spillovers estimated using 200-day rolling samples. Right: Macroeconomic spillovers estimated using 36-month rolling samples. Period: 01/01/2015-02/28/2021 

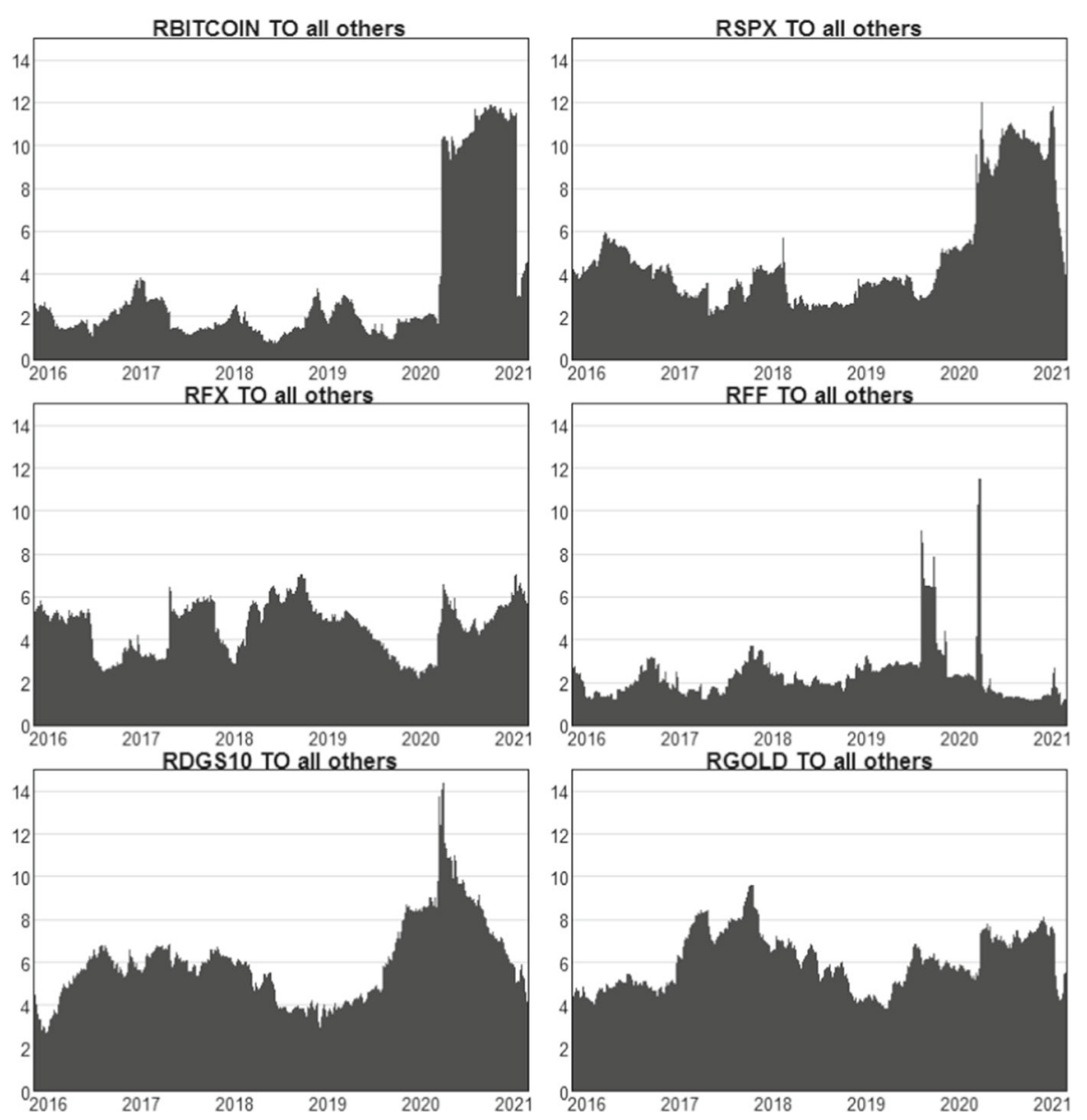

Fig. 5 Directional spillovers TO all others. Note: Figure 5 displays the directional spillovers TO all others from Eq. 7. Period: 01/01/2015-02/28/2021

The sensitivity of the results is also checked by including two influential variables, namely, VIX and WTI. Indeed, given the high level of perceived risk (as measured by VIX that surged at $82.69 \%$ on March 16, 2020) and the subsequent decline in industrial activity (as reflected by the WTI that dropped to $\$ 28.96$ per barrel on March 16, 2020, and even accidentally reached, on April 20, 2020, a negative price of -\$36.98), we include both variables along with the six others to gauge if the results change substantially. Unreported ${ }^{14}$ results show that even if these variables are influential, they do not change the core findings around the surge in spillovers on March 2020 from Fed Funds rates to Bitcoins. Put together, these results document the existence of strong spillover effects from RFF to RBITCOIN the week after the Fed Funds rate dramatic cuts on March 2020, a situation that has not been equivalent among all pairs of financial assets studied.

14 Available upon request. 

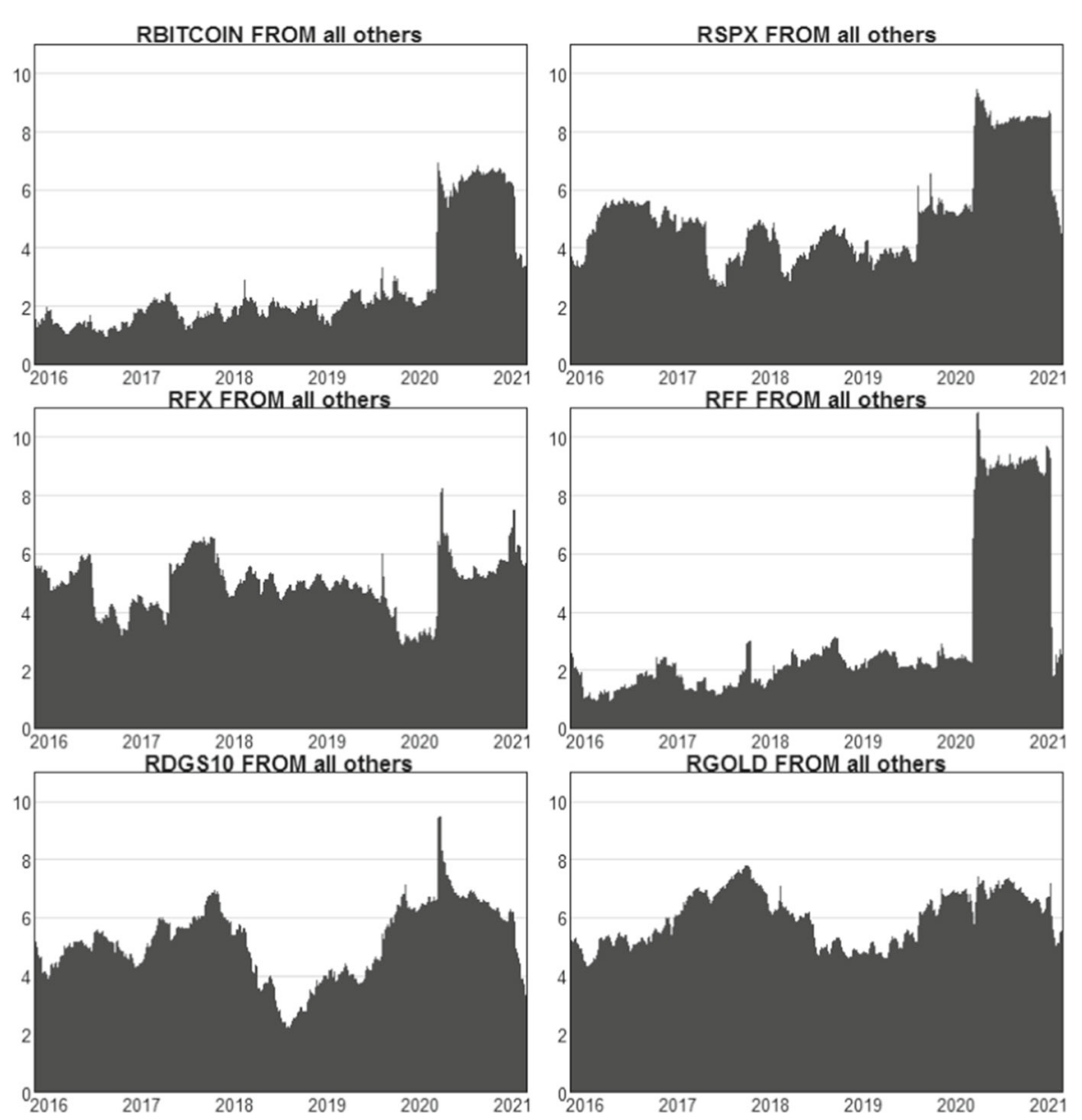

Fig. 6 Directional spillovers FROM all others. Note: Figure 6 displays the directional spillovers FROM all others from Eq. 6. Period: 01/01/2015-02/28/2021

This test with financial daily data is complemented with a test on macroeconomic monthly data in Table 6, involving Bitcoins and Fed Fund rates. Figure 4 displays the total macroeconomic spillovers; the observed net surge begins in August 2020 for macroeconomic variables. The total (nondirectional) spillover index $(63.75 \%)$ is much higher than that for financial data $(15.41 \%)$, which means that $63.75 \%$ of the log-returns forecast error variance in macroeconomic variables comes from spillovers. Concerning own variance shares, RBITCOIN (70.38) still has the highest level.

Regarding the gross directional spillovers “TO” others, Initial Claims and Fed Funds rates are by far the highest transmitters of spillovers, with 149.41 for RCLAIM and 92.33 for RFF. RBITCOIN is mainly influenced by RPAYROLL (10.62), RCLAIM (6.94), and RFF (4.48).

Regarding the gross directional spillovers "FROM" others, RBITCOIN is the lowest receiver of spillovers (29.62), while RPAYROLL is by far the highest receiver (89.66). 

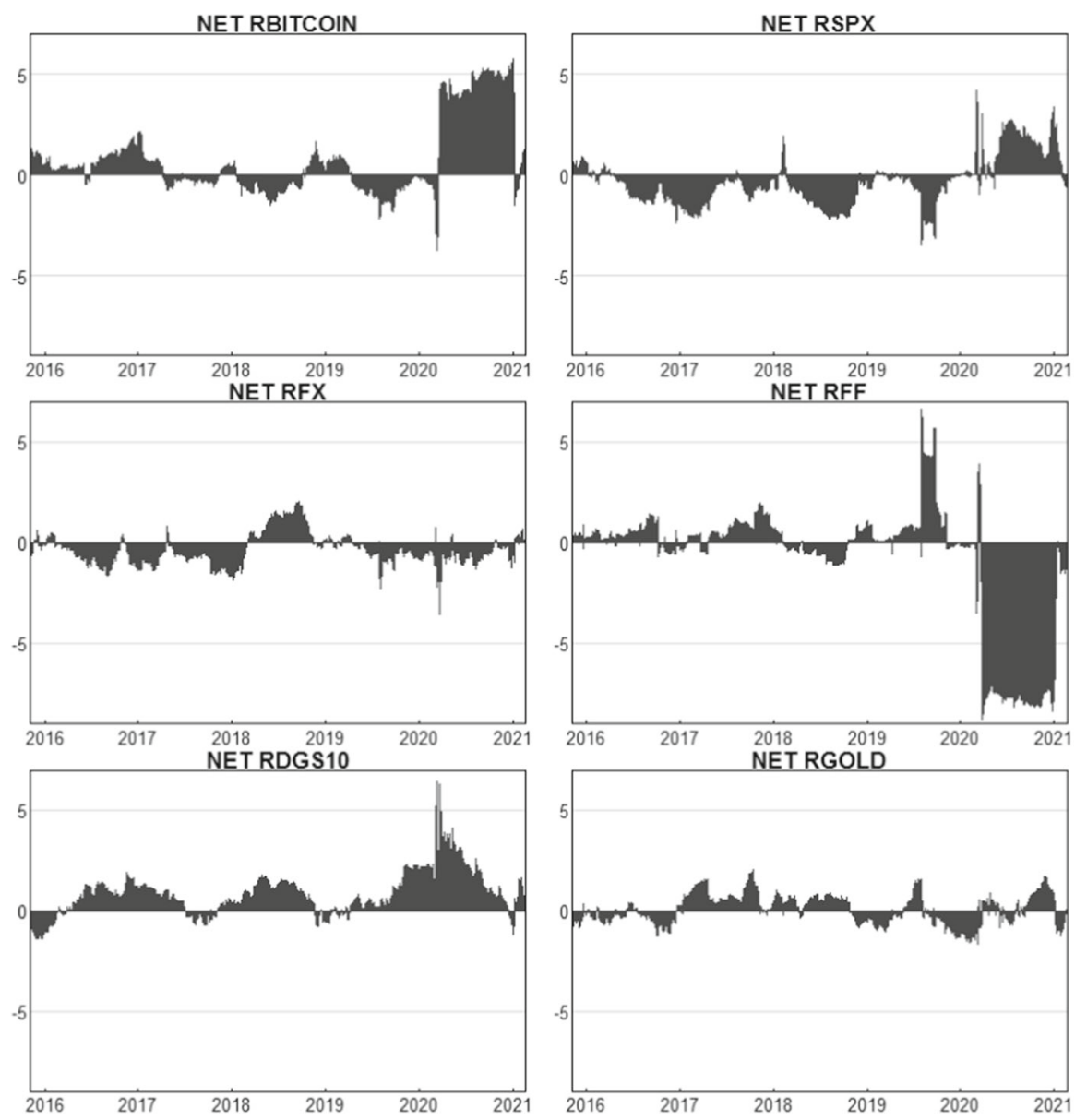

Fig. 7 Net spillovers. Note: Figure 7 displays the NET spillovers from Eq. 8. Period: 01/01/2015-02/28/2021

Concerning the "Net" directional spillovers, RFRB appears to be the least influential variable (-8.17), whereas RCLAIM is the most influential variable (84.65). Only RCLAIM and RFF have a positive value, which means that they influence more than they are influenced.

In summary, Table 3 and Fig. 3 unveil the direct (lagged) and indirect (contemporaneous) influence of RFF on RBITCOIN since the rolling $R^{2}$ exhibits a peak exactly on the day (March 13, 2020) and on the subsequent days of the massive Fed Funds cuts (-150 bp). Table 4 documents the existence of threshold effects and higher-order (contemporaneous) effects between RFF and RBITCOIN. Table 5 and Figs. 4, 5, 6, 7 , and 8 provide evidence that both total (among all six financial assets) and directional spillovers (between RFF and RBITCOIN) were relatively weak until March 23, 2020, which opened the door of a turbulent period. This period corresponds to the Fed Funds rate large cut in response to the COVID-19 outbreak. Table 6 reveals the large 

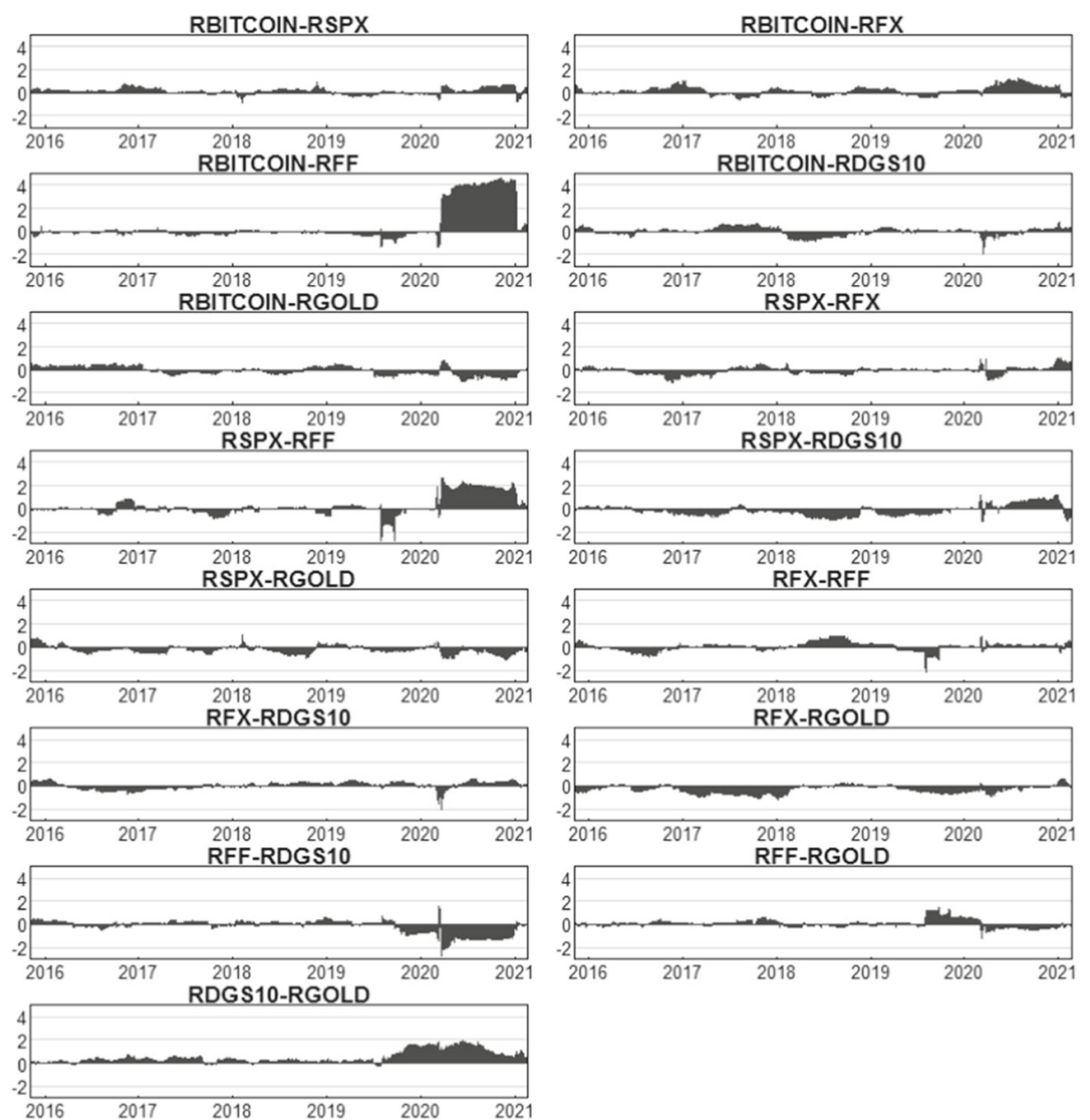

Fig. 8 Net pairwise spillovers. Note: Figure 8 displays the NET PAIRWISE spillovers from Eq. 9. Period: $01 / 01 / 2015-02 / 28 / 2021$

influence of macroeconomic variables on RBITCOIN, in particular, RPAYROLL and RCLAIM.

\subsection{Discussion}

This research highlights how complex the puzzle behind the Bitcoin price surge is. It mainly argues that one potential explanation comes from the Fed Funds rate. On the one hand, Bitcoin seems to obey most of the time to its own price return dynamic as evidenced by the high level of own variance shares of RBITCOIN. This may explain why few studies have been devoted to Bitcoin price returns and mostly to Bitcoin price volatility; indeed, by exploring the volatility side, more interactions among markets may be found, which makes it easier to report significant results. On the other hand, if Bitcoins look like pertaining to a segmented market, it may still be influenced either 
Table 6 Spillovers matrix with macroeconomic data

\begin{tabular}{|c|c|c|c|c|c|c|c|c|}
\hline & RBITCOIN & RFF & RCPI & RPAYROLL & L RINDPRO & RFRB & RCLAIM & $\begin{array}{l}\text { Contribution } \\
\text { FROM others }\end{array}$ \\
\hline RBITCOIN & 70.38 & 4.48 & 3.39 & 10.62 & 2.34 & 1.85 & 6.94 & 29.62 \\
\hline RFF & 3.57 & 29.61 & 5.51 & 11.87 & 13.59 & 3.67 & 32.18 & 70.39 \\
\hline RCPI & 0.96 & 18.03 & 21.39 & 17.10 & 11.87 & 2.10 & 28.55 & 78.61 \\
\hline RPAYROLL & 2.52 & 22.02 & 6.85 & 10.34 & 17.52 & 5.61 & 35.13 & 89.66 \\
\hline RINDPRO & 2.40 & 21.76 & 7.77 & 7.74 & 20.75 & 6.58 & 33.00 & 79.25 \\
\hline RFRB & 0.36 & 4.28 & 2.55 & 6.01 & 7.15 & 66.04 & 13.61 & 33.96 \\
\hline RCLAIM & 2.99 & 21.76 & 5.71 & 12.73 & 15.60 & 5.97 & 35.24 & 64.76 \\
\hline $\begin{array}{l}\text { Contribution TO } \\
\text { others }\end{array}$ & 12.81 & 92.33 & 31.77 & 66.07 & 68.06 & 25.79 & 149.41 & 446.24 \\
\hline $\begin{array}{l}\text { Directional } \\
\text { including own }\end{array}$ & 83.18 & 121.95 & 53.16 & 76.42 & 88.81 & 91.83 & 184.65 & TSI: $63.75 \%$ \\
\hline $\begin{array}{l}\text { Net Directional } \\
\text { Connectedness }\end{array}$ & -16.82 & 21.95 & -46.84 & -23.58 & -11.19 & -8.17 & 84.65 & \\
\hline
\end{tabular}

The results for the spillover directional model applied on macroeconomic data with monthly frequency. The results are based on vector autoregressions (order 2) and generalized variance decompositions of 6month ahead log-returns forecast errors; spillovers are estimated using 36-month rolling samples. The contributions to others and from others are the "TO" and "FROM" directional spillovers. The FROM minus TO differences corresponds to the Net spillovers. The Total Spillover Index (lower right corner) is the "FROM" column sum relative to the "Directional including own" row sum expressed as a percentage. Period: 01/01/2015-02/28/2021

directly by stock indexes and gold markets or indirectly by Fed rates with delayed effects through other macrofinancial channels. This was the case in March 2020, when the coronavirus pandemic shuttered small businesses and sent workers home. At the stage of the pandemic, insured unemployment comoved strongly with payroll employment (see a discussion by Cajner et al. 2020), which explains not only the prominence of RPAYROLL and RCLAIM variables given the mounting layoffs but also the economic support of the US Federal Reserve through interest rate cuts. This monetary support through the Fed Funds rate could be interpreted as a policy response to the worsening of labor market conditions. Bitcoins also seem temporarily influenced by Fed rates through spillovers among price returns on some specific dates. It is also directly influenced by Fed Funds rates at higher orders, which explains why a linear regression does not capture the effects of the contemporaneous interest rate cut. To wrap up the discussion, the literature seems to miss several effects of the Fed Funds rate on the Bitcoin: threshold, higher order, and spillover. This might explain why there are many studies that ignore Fed Funds rates among their explanatory variables.

\section{Conclusion}

This study investigates the influence of Fed Funds rates on the price dynamics of Bitcoins. For that matter, six representative assets are considered over the period 
of January 2015 to February 2021: Bitcoin, Fed Funds rate, S\&P 500, 10-year US Treasury Bond, USD/EUR exchange rate, and Gold.

The methodology is based on alternative settings: from linear contemporaneous or lagged relations and nonlinear relations with thresholds and higher-order effects to spillover effects. The spillover effect comes from the Diebold and Yilmaz (2012) model, which is based on a generalized VAR framework to produce variance decompositions that are invariant to ordering.

The main finding supports the idea that the Fed Funds rates have delayed, threshold, higher order, and spillover effects on Bitcoins. For instance, evidence is provided that the Fed Funds rate cut, which occurred in March 2020 as a policy response to the coronavirus outbreak, given the worsening of labor market conditions, did affect the Bitcoin dramatic run-up that overshot its previous all-time high. An interesting avenue for future research is to explore the lead-lag relation between cryptocurrencies and Fed policy under specific regimes in interest rates.

Funding None.

\section{Declarations}

\section{Conflicts of interest None.}

Data availability Data will be provided if requested by editors.

Code availability Code for data analysis is provided if requested by editors. The source of the code is from R-project software.

Ethics approval This material is the author' own original work. It has not been previously published elsewhere. It is not currently being considered for publication elsewhere.

\section{References}

Adcock R, Gradojevic N (2019) Non-fundamental, non-parametric Bitcoin forecasting. Phys A Stat Mech Appl 53:121727

Atsalakis GS, Atsalaki IG, Pasiouras F, Zopounidis C (2019) Bitcoin price forecasting with neuro-fuzzy techniques. Eur J Oper Res 276:770-780

Bai J, Perron P (1998) Estimating and testing linear models with multiple structural changes. Econometrica 66:47-78

Bai J, Perron P (2003) Computation and analysis of multiple structural change models. J Appl Econom $18: 1-22$

Balvers RJ, McDonald B (2021) Designing a global digital currency. J Int Money Finance 111:102317

Barunik J, Kocenda E, Vacha L (2016) Asymmetric connectedness of the U.S. stock market: How does bad and good volatility spill over the U.S. stock market? J Financ Mark 27:55-78

Bouri E, Das M, Gupta R, Roubaud D (2018) Spillovers between Bitcoin and other assets during bear and bull markets. Appl Econ 50:5935-49

Cajner T, Figura A, Price BM, Ratner D, Weingarden A (2020) Unemployment claims with job losses in the first months of the COVID-19 crisis, Finance and Economics Discussion Series 2020-055. Board of Governors of the Federal Reserve System, Washington

Chaum D (1983) Blind signatures for untraceable payments. In: Chaum D, Rivest RL, Sherman AT (eds) Advances in cryptology. Springer, pp 199-203 
Chen W, Xu H, Jia L, Gao Y (2021) Machine learning model for Bitcoin exchange rate prediction using economic and technology determinants. Int J Forecast 37:28-43

Cieslak A, Vissing-Jorgensen A (2020) The economics of the Fed put. National Bureau of Economic Research, Number 26894

Conrad C, Custovic A, Ghysels E (2018) Long- and short-term cryptocurrency volatility components: a GARCH-MIDAS analysis. J Risk Financ Manag 11:23

Corbet S, Larkin C, Lucey B, Meegan A, Yarovaya L (2020) Cryptocurrency reaction to FOMC announcements: evidence of heterogeneity based on blockchain stack position. J Financ Stabil 46:100706

D'Amico S, Farka M (2011) The Fed and the stock market: an identification based on intraday futures data. J Bus Econ Stat 29:126-137

Diebold F, Yilmaz K (2009) Measuring financial asset return and volatility spillovers, with application to global equity markets. Econ J 119:158-171

Diebold F, Yilmaz K (2012) Better to give than to receive: predictive directional measurement of volatility spillovers. Int J Forecast 28:57-66

Diebold F, Yilmaz K (2014) On the network topology of variance decompositions: measuring the connectedness of financial firms. J Econom 182:119-134

Do HX, Brooks R, Treepongkaruna S, Wu E (2016) Stock and currency market linkages: new evidence from realized spillovers in higher moments. Int Rev Econ Finance 42:167-185

Dyhrberg AH (2016) Bitcoin, gold and the dollar, a GARCH volatility analysis. Finance Res Lett 16:85-92

Fantacci L, Gobbi L (2021) Stablecoins, Central Bank digital currencies and US Dollar hegemony, accounting, economics, and law: a convivium

Finta MA, Aboura S (2020) Risk premium spillovers among stock markets: evidence from higher-order moments. J Financ Mark 49:100533

Foley S, Karlsen JR, Putnins TJ (2019) Sex, drugs, and bitcoin: How much illegal activity is financed through cryptocurrencies? Rev Financ Stud 32:1798-1853

Gandal N, Hamrick JT, Moore T, Oberman T (2018) Price manipulation in the Bitcoin ecosystem. J Monet Econ 95:86-96

Gillaizeau M, Jayasekera R, Maaitah A, Mishra T, Parhi M, Volokitina E (2019) Giver and the receiver: understanding spillover effects and predictive power in cross-market Bitcoin prices. Int Rev Financ Anal 63:86-104

Gradojevic N, Kukolj D, Adcock R, Djakovic V (2021) Forecasting Bitcoin with technical analysis: a not-so-random forest? Int J Forecast 6:66

Greenwood-Nimmo M, Nguyen VH, Rafferty B (2016) Risk and return spillovers among the G10 currencies. J Financ Mark 31:43-62

Griffin JM, Shams A (2020) Is Bitcoin really untethered? J Finance 75:1913-1964

Gronwald M (2019) Is Bitcoin a commodity? On price jumps, demand shocks, and certainty of supply. J Int Money Finance 97:86-92

Hayek FA (1990) Denationalisation of money: the argument refined. The Institute of Economic Affairs

Huynh TLD, Nasir MA, Vo XV, Nguyen TT (2020) Small things matter most: the spillover effects in the cryptocurrency market and gold as a silver bullet. N Am J Econ Finance 54:101277

Jang H, Lee J (2018) An empirical study on modeling and prediction of Bitcoin prices with Bayesian neural networks based on blockchain information. IEEE Access 6:5427-5437

Ji Q, Bouri E, Kristoufek L, Lucey B (2021) Realised volatility connectedness among Bitcoin exchange markets. Finance Res Lett 38:101391

Koop G, Pesaran MH, Potter SM (1996) Impulse response analysis in non-linear multivariate models. J Econom 74:119-147

Koutmos D (2020) Market risk and Bitcoin returns. Ann Oper Res 294:453-477

Liu Y, Tsyvinski A (2021) Risks and returns of cryptocurrency. Rev Financ Stud 34:2689-2727

Lyocsa S, Molnar P, Plihal T, Siranova M (2020) Impact of macroeconomic news, regulation and hacking exchange markets on the volatility of bitcoin. J Econ Dyn Control 119:103980

Mamun Md, Uddin GS, Suleman MT, Kang SH (2020) Geopolitical risk, uncertainty and Bitcoin investment. Phys A Stat Mech Appl 540:123107

Nakamoto S (2008) Bitcoin: a peer-to-peer electronic cash system, white paper

Obstfeld M (2021) Two challenges from globalization. J Int Money Finance 110:102301

Panagiotidis T, Stengos T, Vravosinos O (2018) On the determinants of bitcoin returns: a lasso approach. Finance Res Lett 27:235-240 
Panagiotidis T, Stengos T, Vravosinos O (2019) The effects of markets, uncertainty and search intensity on bitcoin returns. Int Rev Financ Anal 63:220-242

Pesaran MH, Shin Y (1998) Generalized impulse response analysis in linear multivariate models. Econ Lett 58:17-29

Poole W (2008) Market bailouts and the "Fed Put." Federal Reserve Bank of St. Louis Review, March/April, pp 65-74

Rigobon R, Sack B (2004) The impact of monetary policy on asset prices. J Monet Econ 51:1553-1575

Son H, Fong Y (2021) Fast grid search and bootstrap-based inference for continuous two-phase polynomial regression models. Environmetrics 32:e2664

Symitsi E, Chalvatzis KJ (2018) Return, volatility and shock spillovers of Bitcoin with energy and technology companies. Econ Lett 170:127-30

Wang GJ, Xie C, Wen D, Zhao L (2019) When Bitcoin meets economic policy uncertainty (EPU): measuring risk spillover effect from EPU to Bitcoin. Finance Res Lett 31:489-497

Xu Q, Zhang Y, Zhang Z (2021) Tail-risk spillovers in cryptocurrency markets. Finance Res Lett 38:101453

Publisher's Note Springer Nature remains neutral with regard to jurisdictional claims in published maps and institutional affiliations. 